\title{
Dengue is spreading alarmingly in Nepal: Integrated efforts are required for Prevention and Control
}

\section{Distribution of dengue fever in Nepal}

Nepal is an endemic zone for five major vector borne diseases, namely Malaria, Lymphatic filariasis, Japanese encephalitis, Visceral leishmaniasis and Dengue fever. ${ }^{1}$ Prevention and control of these vector borne diseases pose a constant threat to the public health system. ${ }^{2}$ In recent years, dengue emerged as the disease of public health challenge since the cases were notified in 2005. Its outbreaks were reported in 2006 and 2010; and the cases are increasing since last year. In this year, 5095 cases were reported till 24 Bhadra $2076 .{ }^{3}$ Increase in the case load indicate that the endemic status possibly turn into epidemic if not prevented and controlled in time. Table below shows the cases reported in different fiscal years.

\section{Table 1: Distribution of Dengue in Nepal}

\begin{tabular}{lrrrrrrr}
\hline \multirow{2}{*}{ Provinces } & \multicolumn{7}{c}{ Fiscal Years (BS) } \\
\cline { 2 - 8 } & $\mathbf{2 0 7 0 / 7 1}$ & $\mathbf{2 0 7 1 / 7 2}$ & $\mathbf{2 0 7 2 / 7 3}$ & $\mathbf{2 0 7 3 / 7 4}$ & $\mathbf{2 0 7 4 / 7 5}$ & $\mathbf{2 0 7 5 / 7 6}$ & $\mathbf{2 0 7 6 / 7 7 ^ { * }}$ \\
\hline 1 & 8 & 5 & 418 & 543 & 19 & 3152 & 831 \\
2 & 114 & 17 & 43 & 609 & 12 & 12 & 39 \\
3 & 141 & 75 & 781 & 95 & 64 & 125 & 3126 \\
Gandaki & 0 & 8 & 3 & 24 & 568 & 26 & 972 \\
5 & 13 & 24 & 242 & 836 & 120 & 96 & 97 \\
Karnali & 0 & 0 & 23 & 3 & 1 & 1 & 3 \\
Sudur Paschim & 26 & 5 & 17 & 1 & 27 & 12 & 27 \\
Total & 302 & 134 & 1527 & 2111 & 811 & 3424 & 5095 \\
\hline
\end{tabular}

*As of 24 Bhadra 2076 BS (Source: Epidemiology and Disease Control Division, Nepal)

\section{Figure 1: Trend of Dengue Cases in Nepal}

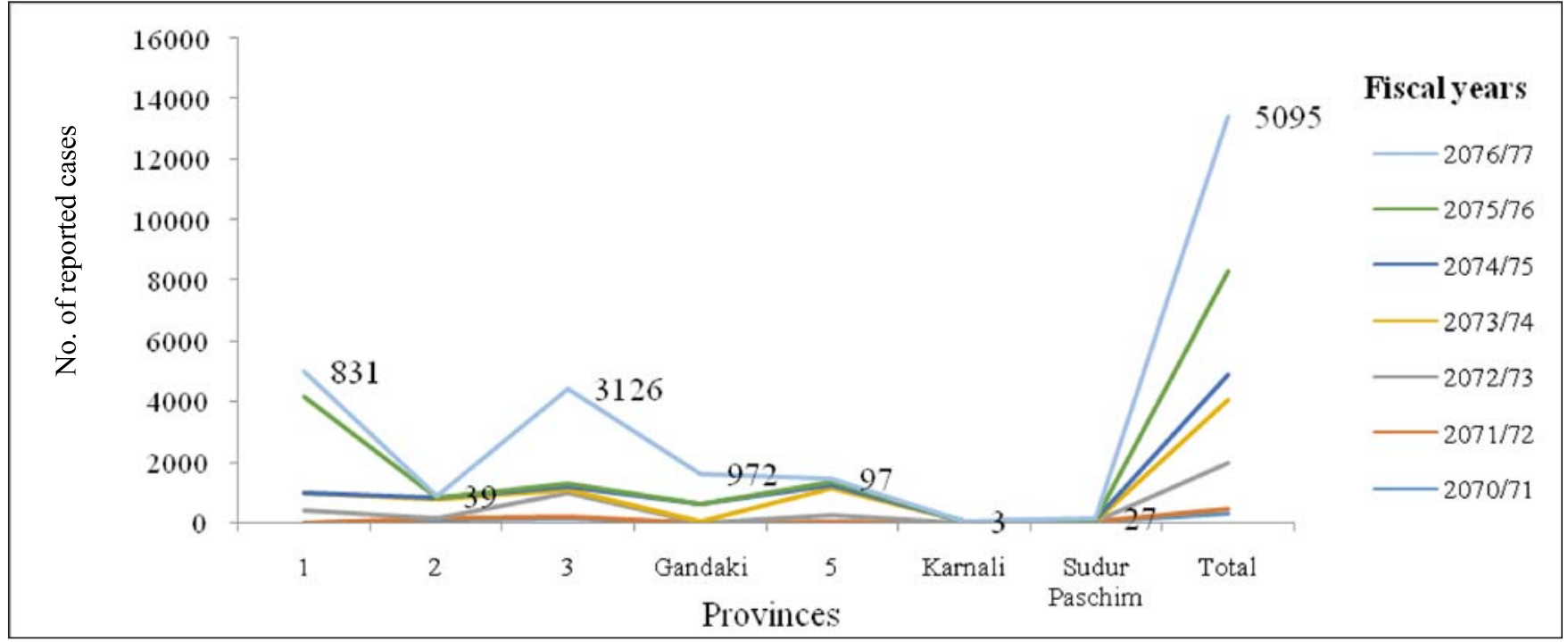


As indicated in table 1 and figure 1, annual case incidences of the dengue show the irregular pattern in its occurrence. Except Karnali province, dengue is spreading at an alarming rate in other provinces with large clustering of cases in province no.1, 3 and Gandaki. In total, there is incremental trend in its incidence which indicates the necessity of deliberate study of dengue epidemiology.

\section{Epidemiological Characteristics}

Dengue is caused by Arbo virus. It is transmitted to humans by the bite of female Aedes aegypti mosquito. It is likely to bite early in the morning or before sunset. Denuge transmitting mosquitoes grow with improper waste management. These mosquitoes lay eggs in water that accumulate in discarded tyres, bottles and cans, flower pots, air conditioners, rainwater collected in urban areas and waterlogged areas. Dengue virus is expected to remain active till December, so cases of the dengue may be seen even after December if it is not controlled and prevented in time.

\section{Prevention and Control of Dengue}

There is no specific medicine to cure the dengue, the only way to stay safe from this disease is to destroy mosquitoes and their breeding areas; keep the local environment neat and clean; always use mosquito nets; and apply mosquito repellents.

Irregular pattern in the occurrence of dengue made complex to understand its epidemiology. Health system of Nepal has adopted the "mosquito search and destroy campaign", however; these efforts could not sufficiently prevented and controlled the dengue. It has further added challenges in its prevention and control. Prevention and control of dengue is publicly perceived to be the health sector's responsibility. This perception is incomplete because the occurrence, transmission and its prevention is highly dependent on the public behavior. Therefore, its prevention requires application of multidisciplinary behavior change interventions with multi-sectoral involvements. Awareness raising campaigns at the institutional level and communities, destroying the habitat of the mosquito and their breeding sites and adoption of protective behaviors are the key concerns of dengue prevention. Hence, dengue prevention is not only the health sector's responsibility but rather it is social responsibility.

\section{REFERENCES}

1. Dhimal M, Ahrens B, Kuch Ulrich. Climate Change and Spatiotemporal Distributions of Vector-Borne Diseases in Nepal - A Systematic Synthesis of Literature. PLoS One. 2015; 10(6): e0129869

2. World Health Organization, Country Office for Nepal. WHO Country Cooperation Strategy Nepal, 2013-2017. Available from www.searo. who.int/nepal/ccs_2013-17.

3. Epidemiology and Disease Control Division, Nepal. Dengue Control Program. Available from http://edcd.gov.np/section/dengue-controlprogram (cited on 13 September 2019).

4. Dhakal S. Dengue spreading at alarming rate nationwide. https:// thehimalayantimes.com/kathmandu/dengue-spreading-at-alarmingrate-nationwide/ (Cited on 16 September 2019).

5. Editorial. Dangerous Dengue. http://therisingnepal.org.np/ news/33813 (Cited on 16 September 2019).

\section{Correspondence:}

Dr. Damaru Prasad Paneru

Editor-In-Chief, Journal of Health and Allied Sciences

E-mail: damaru.paneru@gmail.com 